\title{
Luces y sombras del tiempo profundo. Venezuela y el patrimonio paleontológico
}

Hyram A. Moreno | Museo de Ciencias-Fundación Museos Nacionales, Caracas (Venezuela)

URL de la contribución <www.iaph.es/revistaph/index.php/revistaph/article/view/4196>

\section{A manera de introducción}

El statu quo en materia de protección jurídica y conservación del patrimonio paleontológico en la República Bolivariana de Venezuela, está sustentada por la vigente Ley de Protección y Defensa del Patrimonio Cultural (LPDPC, 1993), amparando a otros bienes que integran el amplio abanico del patrimonio cultural de la nación. Sin embargo, el patrimonio paleontológico fue referido de manera temprana en el año de 1945, en el Capítulo II (Del patrimonio arqueológico y paleontológico de la Nación) de la derogada Ley de Protección y Conservación de Antigüedades y Obras Artísticas de la Nación.

En ambas normas legales -mutatis mutandi- el desarrollo del concepto de patrimonio paleontológico y su alcance es limitado y aplaza, sin ambages, la especificidad formal y factual de tal categoría de bien cultural. Así mismo, algunos vacíos legales -si vale el uso de la figura- fueron advertidos y llevaron a posteriori a una normativa de rango sublegal que intentaría enmendarlos. Verbigracia, las denominadas providencias administrativas: n. ${ }^{\circ}$ 012/05 del 27 de julio de 2005, Gaceta Oficial de la República Bolivariana de Venezuela, n. ${ }^{\circ} 38.237$; 029/12 del 15 de octubre de 2012, Gaceta Oficial de la República Bolivariana de Venezuela, n. ${ }^{\circ} 40.028$ y 025/13 del 16 de agosto de 2013, Gaceta Oficial de la República Bolivariana de Venezuela, n. $\left.{ }^{\circ} 40.230\right)$. Y de manera concreta la "redefinición" de patrimonio paleontológico (n. ${ }^{\circ}$ 025/13), contigua a otras categorías incorporadas en el Registro General del Patrimonio Cultural de Venezuela.

\section{Patrimonio cultural, rocas y estratos}

El marco amplio de protección del patrimonio cultural está instaurado en la Constitución de la República
Bolivariana de Venezuela (1999) y su gestión pública compete, como ente rector y de manera taxativa, al Instituto del Patrimonio Cultural (IPC), creado en el año de 1993 (LPDPC). Su esfera de acción es vasta y comprende tanto al patrimonio cultural per se como el patrimonio natural, retomando las definiciones emanadas de la Convención de la UNESCO (París, 1972) sobre Patrimonio Mundial (IPC, 2001 y 1997).

En ese convenio, el patrimonio natural es propuesto como las formaciones geológicas y fisiográficas. Es decir, lugares, zonas o paisajes naturales que tienen valores estéticos o científicos. Visto desde la geodiversidad, las formaciones geológicas son testigos instrumentales de la geodinámica y memoria geológica del planeta. Así mismo, y en una magnitud apreciable, portadoras de evidencias tangibles y discretas -a veces únicas e irremplazables- de la evolución e historia natural de la biosfera. En palabras de S. J. Gould (1992), son las evidencias del tiempo profundo.

En efecto, la noción de patrimonio paleontológico debería comprender, en sentido lato, al conjunto de yacimientos, localidades, afloramientos y secciones tipo fosilíferas (estratos, estratotipos, unidades litoestratigráficas o bioestratigráficas) conocidos y estudiados. Circunscribiéndola a la definición canónica de patrimonio natural (accidente objetivo, DÍAZ-MARTÍNEZ; VEGAS; CARCAVILLA et ál., 2016).

Desde otra perspectiva, consideraría al patrimonio mueble: las colecciones de investigación, ejemplares tipo (tipos portanombre), exposiciones, material expográfico o didáctico (socialización del patrimonio), así como los fondos de colección resguardados en museos paleon- 
tológicos, de ciencias naturales (MELÉNDEZ; SORIA, 1999) o en otras instituciones culturales tanto públicas como privadas. Convergiendo ésta, si se quiere, en el accidente subjetivo o la concesión de valores intangibles (socioculturales). Empero, ambos son componentes interdependientes y complementarios; es decir, cara y cruz del concepto.

Para el caso venezolano. La norma sublegal lo desarrolla en los elementos conservados como: plantas; vertebrados; invertebrados y huellas de actividad biológica o icnofósiles (n. ${ }^{\circ}$ 025/13). Incorporando, además, los fondos de colección en manos de particulares que existan en el país. Siendo esto redundante a la postre; cabría señalar que el artículo $35^{\circ}$ (LPDPC, Título IV, 1993) declara que los bienes del patrimonio paleontológico (y arqueológico) son propiedad del Estado.

Como corolario de lo expuesto. La normativa legal debe expresar en forma explícita y sistémica esa realidad y sus múltiples aristas. En tanto, como condición medular, establecer los lineamientos y la reglamentación para su protección, conservación y puesta en valor; más aún cuando el contingente registro fósil es una pequeña muestra de la biota del pasado, distorsionada y sesgada por procesos y mecanismos de alteración tafonómica.

Así mismo, tal casuística propendería a visibilizar la gestión de los fondos de colección, vinculada de manera estrecha con las comunidades locales e instituciones de servicio cultural; patentizando la impostergable necesidad de inventariar, registrar y documentar (catalogar) el patrimonio paleontológico como una buena práctica de conservación preventiva; y contribuyendo de manera capital a la valoración sociocultural, comprensión y uso público del conocimiento paleontológico. Siendo esto, en última instancia, el "ambiente sedimentario" que le otorgará sentido y pertinencia social como bienes del patrimonio paleontológico.

\section{Comprensión, participación y puesta en uso}

Desde esta reflexión, es axiomática la participación de las comunidades a nivel local, regional o nacional, y ese

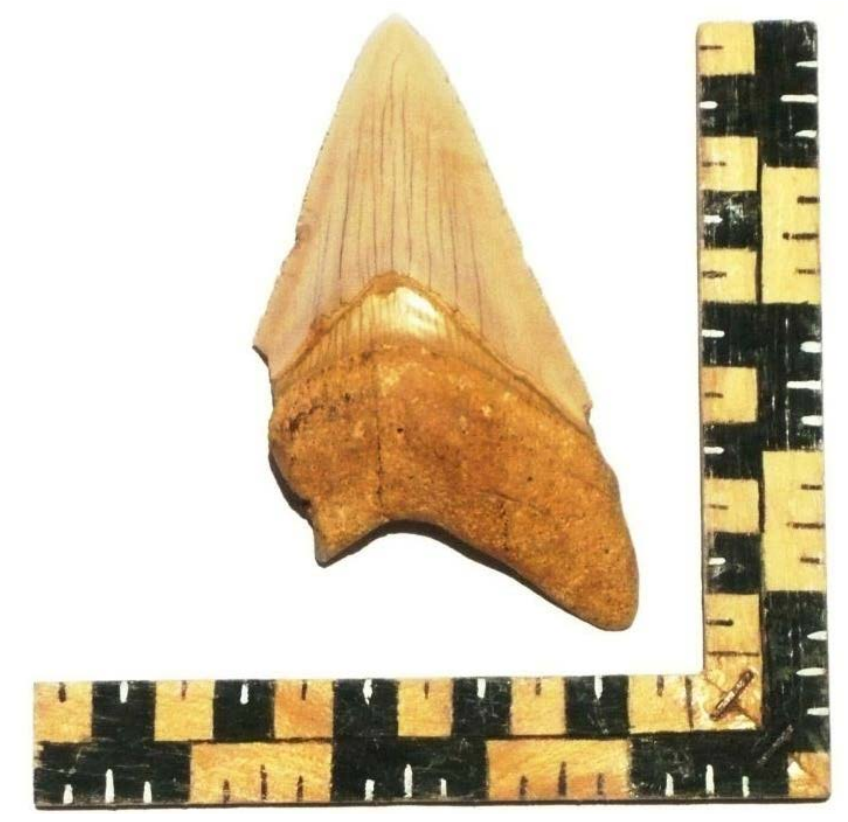

Diente de megalodón encontrado en el cauce del río Coro, cerca de la población de Caujarao, Venezuela. Forma parte de la colección del Museo Comunitario que la comunidad de Caujarao promueve en la Red de Museos Comunitarios, Casas y Árboles de la Memoria, Senderos de Interpretación y Significación del Estado Falcón (RMC, CAM, SISEF) | foto Camilo Morón

contexto tiene un notorio peso específico para la comprensión y puesta en uso. Por tanto, la ciudadanía y la comunidad científica deben instaurar vínculos tangibles y participar en la toma de decisiones y control de la ejecución y seguimiento de los criterios y medidas o figuras de protección adoptadas. En Venezuela, la LPDPC establece la obligación de la ciudadanía en la defensa del patrimonio cultural (Artículo $2^{\circ}, 1993$ ).

Sin embargo, el actual escenario venezolano es una larga y sinuosa competición de resistencia, plagada de obstáculos. Las instancias de articulación y ejecución entre el Estado, el ente rector y las comunidades son laxas o tienden a disgregarse; diluyendo grosso modo las responsabilidades o postergando, de manera indefinida, las perentorias acciones de salvaguarda. En otro aspecto no menos significativo, los exiguos recursos financieros y equipos disponibles, incluyendo el talento técnico y profesional, son insuficientes (o inexistentes) y obstaculizan toda aquella posibilidad de introducir nue- 
a debate El marco legal para la protección del patrimonio paleontológico. ¿Qué pasa en tu comunidad?

vas tecnologías o en grado sumo, avanzar y profundizar en localidades paleontológicas de comprobado valor e importancia; lo cual, arrastra mayores dificultades para el propio trabajo científico y las acciones tendentes a su conservación y puesta en uso.

Vista la diversidad y riqueza paleobiológica del territorio venezolano hasta ahora hallada y estudiada; esta síntesis esbozaría una pesada deuda cultural y científica, hasta tanto avancemos en la construcción de una cultura patrimonial.

\section{BIBLIOGRAFÍA}

- díAZ-MARTíneZ, E.; VEgAS, J.; CARCAVILLA, L.; GARCÍA-CORTÉS, A. (2016) Base conceptual, estado de la cuestión y perspectivas de la gestión y conservación del patrimonio paleontológico. En MELÉNDEZ, G.; NÚÑEZ, A.; TOMÁS, M. (ed.) Actas de las XXXII Jornadas de la Sociedad Española de Paleontología. Madrid: Instituto Geológico y Minero de España, 2016 (Cuadernos del Museo Geominero; 20)

- GACETA Oficial República Bolivariana de Venezuela, n. ${ }^{\circ}$ 40.230. Caracas, viernes 16 de agosto de 2013

- GACETA Oficial República Bolivariana de Venezuela, n. ${ }^{\circ}$ 40.028. Caracas, lunes 15 de octubre de 2012

- GACETA Oficial República Bolivariana de Venezuela, n. ${ }^{\circ}$ 38.237. Caracas, miércoles 27 de julio de 2005

- GACETA Oficial República Bolivariana de Venezuela, n. ${ }^{\circ}$ 5.453 Extraordinaria. Constitución de la República Bolivariana de Venezuela. Con exposición de motivos. Caracas, viernes 24 de marzo de 2000

- GOULD, STEPHEN J. (1992) La flecha del tiempo. Mitos y metáforas en el descubrimiento del tiempo geológico. Madrid: Alianza Editorial, 1992

- LEY de Protección y Defensa del Patrimonio Cultural y su reglamento. Instructivo que regula el Registro General del Patrimonio Cultural Venezolano y el manejo de los bienes que lo integran (2006) Caracas: Instituto del Patrimonio Cultural, 2006

- MELÉNDEZ, G.; SORIA, M. (1999) Situación actual del patrimonio paleontológico en España. $\mathrm{PH}$ Boletín, n. ${ }^{\circ}$ 29, 1999, pp. $128-141$

- PATRIMONIO Cultural a nuestro alcance (2001) Caracas: Instituto del Patrimonio Cultural

- PROYECTO Inventario Nacional del Patrimonio Cultural. Plataforma conceptual (1997) Caracas: Instituto del Patrimonio Cultural, 1997 